Published in final edited form as:

Radiat Res. 2019 January ; 191(1): 43-51. doi:10.1667/RR15189.1.

\title{
Enhanced Pharmacological Ascorbate Oxidation Radiosensitizes Pancreatic Cancer
}

\author{
Matthew S. Alexandera ${ }^{\text {, Brianne R. O'Leary }}{ }^{\mathrm{a}}$, Justin G. Wilkes ${ }^{\mathrm{a}}$, Adrienne R. Gibson ${ }^{\mathrm{b}}$, Brett \\ A. Wagner ${ }^{\mathrm{b}}$, Juan Du ${ }^{\mathrm{a}}$, Ehab Sarsour ${ }^{\mathrm{b}}$, Rosa F. Hwang ${ }^{\mathrm{c}}$, Garry R. Buettner ${ }^{\mathrm{b}}$, and Joseph J. \\ Cullen $^{\mathrm{a}, \mathrm{d}, \mathrm{e}, 1}$

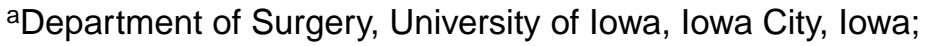 \\ bDepartment of Free Radical and Radiation Biology Program, University of lowa, lowa City, lowa; \\ ${ }^{\mathrm{C} B r e a s t}$ Surgical Oncology, University of Texas MD Anderson Cancer Center, Houston, Texas; \\ dThe University of lowa Holden Comprehensive Cancer Center, lowa City, lowa; \\ eVeterans Affairs Medical Center, lowa City, lowa
}

\begin{abstract}
Pharmacologic ascorbate $\left(\mathrm{P}-\mathrm{AscH}^{-}\right)$is emerging as a promising adjuvant for advanced pancreatic cancer. P-Asc $\mathrm{H}^{-}$generates hydrogen peroxide $\left(\mathrm{H}_{2} \mathrm{O}_{2}\right)$, leading to selective cancer cell cytotoxicity. Catalytic manganoporphyrins, such as MnT4MPyP, can increase the rate of oxidation of $\mathrm{P}-\mathrm{AscH}^{-}$, thereby increasing the flux of $\mathrm{H}_{2} \mathrm{O}_{2}$, resulting in increased cytotoxicity. We hypothesized that a multimodal treatment approach, utilizing a combination of $\mathrm{P}-\mathrm{AscH}^{-}$, ionizing radiation and MnT4MPyP, would result in significant flux of $\mathrm{H}_{2} \mathrm{O}_{2}$ and pancreatic cancer cytotoxicity. P-AscH ${ }^{-}$ with MnT4MPyP increased the rate of oxidation of $\mathrm{P}-\mathrm{AscH}^{-}$and produced radiosensitization in all pancreatic cancer cell lines tested. Three-dimensional (3D) cell cultures demonstrated resistance to $\mathrm{P}-\mathrm{AscH}^{-}$, radiation or MnT4MPyP treatments alone; however, combined treatment with $\mathrm{P}-\mathrm{AscH}^{-}$ and MnT4MPyP resulted in the inhibition of tumor growth, particularly when also combined with radiation. In vivo experiments using a murine model demonstrated an increased rate of ascorbate oxidation when combinations of $\mathrm{P}-\mathrm{AscH}^{-}$with MnT4MPyP were given, thus acting as a radiosensitizer. The translational potential was demonstrated by measuring increased ascorbate oxidation ex vivo, whereby MnT4MPyP was added exogenously to plasma samples from patients treated with $\mathrm{P}-\mathrm{AscH}^{-}$and radiation. Combination treatment utilizing $\mathrm{P}-\mathrm{AscH}^{-}$, manganoporphyrin and radiation results in significant cytotoxicity secondary to enhanced ascorbate oxidation and an increased flux of $\mathrm{H}_{2} \mathrm{O}_{2}$. This multimodal approach has the potential to be an effective treatment for pancreatic ductal adenocarcinoma.
\end{abstract}

\footnotetext{
${ }^{1}$ Address for correspondence: University of Iowa Hospitals and Clinics, 200 Hawkins Drive, 1528 JCP; Iowa City, Iowa 52242; joseph-cullen@uiowa.edu.

Editor's note.

The online version of this article (DOI: 10.1667/RR15189.1) contains supplementary information that is available to all authorized users.
} 


\section{INTRODUCTION}

Ductal adenocarcinoma of the exocrine pancreas (PDAC) represents $85 \%$ of all pancreatic neoplasms and is the fourth overall leading cause of cancer-related deaths in the U.S. (1). The National Cancer Institute Surveillance, Epidemiology, and End Results (SEER) data gave estimates of 53,070 new pancreatic cancers and 43,090 deaths for 2017 (2). Unfortunately, the prognosis for PDAC has failed to show major improvement, with current five-year survival rates at merely $7.7 \%$ (2). PDAC remains a highly deadly disease with a notable lack of treatment progress. For the majority of patients with locally advanced or distant disease, chemotherapy (either single or multidrug), radiation therapy and in some instances, a combination chemoradiation therapy, remain options for palliation and improving quality of life (3). However, the side effect profile is significant, highlighting a need for sensitizing agents capable of selectively increasing tumor toxicity without detrimental consequences to normal tissue. Pharmacological ascorbate (intravenous highdose vitamin $\mathrm{C}, \mathrm{P}-\mathrm{AscH}^{-}$) has demonstrated potential as one such agent with significant PDAC cytotoxicity in vitro and in vivo (4-6). Phase 1 clinical trials using $\mathrm{P}-\mathrm{AscH}^{-}$have shown promise in both PDAC and other aggressive cancers, with very few side effects and suggestion of survival benefit when used for patients with advanced disease (7-9).

Ascorbate functions as an antioxidant for cells and organ systems at physiologic concentrations and $\mathrm{pH}$ by readily donating an electron to potentially harmful free radical species (10). However, at high doses, achievable only by intravenous administration, PAscH- $\mathrm{H}^{-}$becomes a prodrug for delivery of $\mathrm{H}_{2} \mathrm{O}_{2}$ to tissue $(6,10,11)$. Normal cells with a full complement of antioxidant enzymes are capable of managing this oxidative flux while cancer cells become overwhelmed (12-14). The fundamental difference between the oncologic drug, $\mathrm{P}-\mathrm{AscH}^{-}$, and oral vitamin $\mathrm{C}$ is the resulting bioavailability (15). Millimolar plasma concentrations are required to generate the extracellular oxidative flux necessary for chemotherapeutic effect, a level only achievable via parenteral administration (16).

The oxidative consequences initiated by $\mathrm{P}-\mathrm{AscH}^{-}$have been extensively investigated by our laboratory and others. The dominant form of $\mathrm{P}^{-} \mathrm{AscH}^{-}$in physiological settings is the ascorbate monoanion $\left(\mathrm{AscH}^{-}\right)$; it can donate two electrons to $\mathrm{O}_{2}$, forming $\mathrm{H}_{2} \mathrm{O}_{2}$, which leads to cancer cell toxicity (6). In the presence of redox active catalytic metal ions (i.e., iron, copper and manganese), this reaction can be significantly accelerated $(17,18)$.

Manganoporphyrins (MnPs) are molecules formed by manganese cations $\left(\mathrm{Mn}^{3+}\right)$ coordinated with a porphyrin ring. In the presence of ascorbate as a reducing agent, some MnPs can act as superoxide reductases, i.e., $\mathrm{Mn}^{2+}$ can reduce $\mathrm{O}_{2}$ by one electron to form superoxide, an intermediate to the formation of $\mathrm{H}_{2} \mathrm{O}_{2}$. The resulting $\mathrm{Mn}^{3+-} \mathrm{P}$ can be reduced back to $\mathrm{Mn}^{2+}{ }_{-} \mathrm{P}$ by ascorbate to repeat the cycle $(19,20)$. Of the variety of MnPs previously tested, MnT4MPyP demonstrated the greatest effect on ascorbate-induced cytotoxicity in PDAC, consistent with its favorable reduction potential (21). Indeed, MnPs combined with $\mathrm{P}-\mathrm{AscH}^{-}$have demonstrated enhanced cytotoxicity to pancreatic cancer cells in vitro and in vivo by increasing the flux of $\mathrm{H}_{2} \mathrm{O}_{2}$ generated by $\mathrm{P}-\mathrm{AscH}^{-}(21,22)$. Perhaps equally important, MnPs have already been tested in vivo and have shown minimal systemic toxicity (19). Furthermore, they have been shown to have radioprotective properties in normal tissue 
(23). Combined with $\mathrm{PAscH}^{-}, \mathrm{MnPs}$ synergistically enhance cytotoxicity and may be a promising adjuvant to $\mathrm{P}-\mathrm{AscH}^{-}$for the treatment of PDAC.

Ionizing radiation is a standard-of-care treatment for PDAC in many clinical situations, including locally advanced disease, node-positive disease, positive tumor margins and large obstructing tumors. In addition to direct damage, radiation also induces DNA damage in a similar fashion to $\mathrm{P}-\mathrm{AscH}^{-}$, by generating ROS that inflict oxidative damage to proteins, lipids and DNA (24). Previously published work has indicated a synergistic effect between radiation and $\mathrm{P}-\mathrm{AscH}^{-}$resulting in enhanced tumor toxicity and protection of normal cells $(4,25-28)$. The selective cytotoxicity in malignant cells compared to normal cells is thought to be due to several different factors, including low levels of antioxidant enzymes, high endogenous levels of ROS and inefficient DNA repair mechanisms $(6,25-29)$. We hypothesized that MnT4MPyP would enhance the radiation-induced cytotoxicity of PDAC by increasing the rate of oxidation of $\mathrm{PAscH}^{-}$. Our study demonstrates that combination treatment with MnT4MPyP and $\mathrm{P}-\mathrm{AscH}^{-}$radiosensitizes PDAC cells but not normal cells, and generates higher rates of ascorbate oxidation (i.e., higher fluxes of $\mathrm{H}_{2} \mathrm{O}_{2}$ ), which increases cancer cell toxicity in cell culture and simulated tissue microenvironments. Furthermore, in tumor xeno-grafts there were increased levels of $\mathrm{Asc}^{\circ-}$ in blood and decreased tumor volumes with combined $\mathrm{P}-\mathrm{AscH}^{-}$, MnT4MPyP and radiation treatment. Finally, the addition of MnT4MPyP to human plasma samples, collected from clinical trial participants receiving $\mathrm{P}-\mathrm{AscH}^{-}$as part of their PDAC treatment, resulted in increases in the rate of ascorbate oxidation, as indicated by the high levels of $\mathrm{Asc}^{-}{ }^{-}$, suggesting translational potential.

\section{MATERIALS AND METHODS}

\section{Cell Culture and Reagents}

The human pancreatic cancer cell lines MIA PaCa-2 and PANC-1 were purchased from ATCC $®$ (Gaithersburg, MD) and passaged fewer than 20 times in DMEM with 10\% fetal bovine serum (FBS) and 1\% penicillin streptomycin (pen-strep). AsPC-1 cells were also obtained from ATCC and passaged in RPMI with 10\% FBS and 1\% pen-strep. The nontumorigenic HPV16-E6E7 immortalized normal pancreatic ductal epithelial cell line H6c7 was purchased from Kerafastt, Inc. (Boston, MA) and were maintained in keratinocyte serum-free media supplemented with epidermal growth factor $(5 \mathrm{ng} / \mathrm{ml})$ and bovine pituitary extract $(50 \mu \mathrm{g} / \mathrm{ml})$. Immortalized tumor-associated pancreatic stellate cells (HPSCs) were obtained from Hwang et al. (30) and maintained in DMEM with 10\% FBS and 1\% penstrep. Mn(III) tetrakis(N-methylpyridinium-4-yl) porphyrin pentachloride (MnT4MPyP) was purchased from Axxora Platform (San Diego, CA) and stored in colored vials at $-20^{\circ} \mathrm{C}$ or dissolved in nanopure water and stored at $4^{\circ} \mathrm{C}$.

\section{Clonogenic Survival Assay}

Stock solutions of ascorbate (1.0 M, pH 7.0) were prepared, as described elsewhere (6). Cell culture treatments were performed by adding MnT4MPyP $(1.0 \mu M)$ and a nutritional dose of P-AscH ${ }^{-}(0.2 \mathrm{mM})$ to fresh media for $1 \mathrm{~h}$ at $37^{\circ} \mathrm{C}$. At the end of $1 \mathrm{~h}$, cells were irradiated to complete the treatment. Clonogenic cell survival was determined in a similar manner to 
previously published works (6). After 10-14 days, surviving colonies were fixed with $70 \%$ ethanol and stained with Coomassie blue; colonies greater than 50 cells were counted under inverted light microscope.

\section{Three-Dimensional (3D) Cell Culture}

Cell-Mate3D ${ }^{\mathrm{TM}}$ was purchased from BRTI Life Sciences (Two Harbors, MN) for 3D cell culture and prepared according to the manufacturer's instructions. MIA PaCa-2-Luc cells (5 $\times 10^{4}$ cells) were mixed with HPSCs $\left(9.5 \times 10^{5}\right.$ cells) in a ratio of $1: 19$ (5\% tumor cells) prior to embedding in the 3D cell culture matrix. PANC-1-Luc cells $\left(1.5 \times 10^{5}\right.$ cells $)$ were mixed with HPSCs $\left(8.5 \times 10^{5}\right.$ cells) in a ratio of 3:17 (15\% tumor cells). Luciferase transfection of MIA PaCa-2 and PANC-1 tumor cells was performed according to methods described elsewhere $(31,32)$. The MIA PaCa-2-Luc 3D cell cultures were kept in DMEM $10 \%$ FBS and 1\% pen-strep. At $24 \mathrm{~h}$ after creation, MIA PaCa-2-Luc cells embedded in the 3D cell cultures were imaged and quantified for baseline bioluminescent signal strength with the AMI-1000 (Spectral Instruments Imaging, Tucson, AZ) and AMIView software. Media was replaced and 3D cell cultures were subsequently treated with MnT4MPyP $(2.0 \mu M)$ and/or P-AscH ${ }^{-}(7.0 \mathrm{mM})$ for $1 \mathrm{~h}$. Irradiations, 1-2 Gy, were performed at the end of $1 \mathrm{~h}$ and the media was replaced and cultures returned to the incubator. After $24 \mathrm{~h}$, cells were reimaged for bioluminescent signal strength. PANC-1-Luc 3D cultures mixed with human pancreatic stellate cells were treated in a similar manner but for three consecutive treatments, each $48 \mathrm{~h}$ apart. Repeated treatments were performed on the PANC-1 cell line to account for higher ascorbate resistance in the PANC-1 cell line conferred by a greater capacity to remove $\mathrm{H}_{2} \mathrm{O}_{2}$ compared to the MIA PaCa-2 cell line (14).

\section{Electronic Paramagnetic Resonance}

Estimates of the steady-state concentration of ascorbate radical, $\left[\mathrm{Asc}^{--}\right]_{\mathrm{ss}}$, in body fluids or media were determined as previously described elsewhere $(7,21,22,33)$. In brief, media samples, mouse whole blood or human plasma were placed into capillary tubes and then placed into a quartz $250 \times 3 \mathrm{~mm}$ inner diameter EPR tube (Wilmad-LabGlass, Vineland, NJ) and centered in an ER 4119HS resonator of a Bruker EMX EPR spectrometer (Bruker BioSpin; Billerica, MA). Spectra were acquired as five signal-averaged scans at room temperature using EPR standard instrument settings. 3-Carboxy-PROXYL (3-CxP CAS no. 2154-68-9, Millipore Sigma, St. Louis, MO), was used as a standard to estimate [Asc $\left.{ }^{\bullet-}\right]_{\mathrm{ss}}$, while considering potential saturation effects (34).

\section{In Vivo Studies}

Thirty-day-old athymic nude mice were obtained from Harlan Sprague-Dawley, Inc. (Indianapolis, IN). Murine protocols were reviewed and approved by the Office of The Institutional Animal Care and Use Committee (IACUC). Mice were injected subcutaneously (s.c.) with $3 \times 10^{6} \mathrm{MIA} \mathrm{PaCa}-2-L u c$ tumor cells. Once tumors reached 3-4 mm in diameter, mice were randomized into one of four experimental treatment groups consisting of 6 to 8 mice: saline alone; saline and irradiation; MnT4MPyP and P-AscH ${ }^{-}$; and MnT4MPyP with $\mathrm{P}-\mathrm{AscH}^{-}$and irradiation. The first day of treatment was considered day 1 and treatments continued for 24 days. Tumor growth was determined by bioluminescence imaging microscopy (mean radiance photons $/ \mathrm{s}^{-1} / \mathrm{cm}^{2}$ ). Saline was given at a dose of $1 \mathrm{M} \mathrm{NaCl}$ daily. 
MnT4MPyP was delivered at $1 \mathrm{mg} / \mathrm{kg}$ per day s.c. $\mathrm{PAscH}^{-}$was delivered at $4 \mathrm{~g} / \mathrm{kg}$ per day intraperitoneally (i.p.). A $5 \mathrm{~Gy}$ dose of radiation was delivered to each flank tumor on days 4,11 and 18 of treatment. Prior to irradiation, mice were anesthetized with $80-100 \mathrm{mg} / \mathrm{kg}$ ketamine i.p. and were shielded with lead blocks to expose only the tumor-bearing flanks. Tumor growth was monitored periodically over the course of treatment using bioluminescent imaging to determine tumor burden.

\section{Ex Vivo Studies}

In separate groups of mice, cardiac blood draws were performed and mouse whole blood was evaluated for $\left[\mathrm{Asc}^{--}\right]_{\mathrm{sS}}$ determination by EPR, as described above. Mice were sacrificed by cervical dislocation. Flank tumors were excised for processing and 4HNE staining. For the human ex vivo experiments, the blood samples were collected during the phase I trial, which was approved by The University of Iowa Human Institutional Review Board and the Protocol Review and Monitoring Committee of the Holden Comprehensive Cancer Center at The University of Iowa Hospitals and Clinics (Iowa City, IA) on December 30, 2014. The trial was listed on www.clinicaltrials.gov under NCT01852890. Informed consent was documented by use of a written consent form approved by the Investigational Review Board and The University of Iowa. Plasma samples were collected at several key points throughout treatment: before patients received any chemoradiation or $\mathrm{P}-\mathrm{AscH}^{-}$treatments; prior to P$\mathrm{AscH}^{-}$infusion during the third and sixth weeks of chemoradiation; and immediately after $\mathrm{P}-\mathrm{AscH}^{-}$infusion in the third and sixth weeks of chemoradiation.

\section{Western Blot}

Mouse tumors were excised and processed to determine 4-hydroxy-2-nonenal-(4HNE) modified proteins as described elsewhere $(4,35)$. 4HNE is a marker of lipid peroxidation and is a well-established marker of tissue oxidative stress (36). Briefly, tissues were homogenized in $1.3 \mathrm{~m} M$ diethylenetriaminepentaacetic acid (DETAPAC), $10 \mathrm{~m} M$ butylated hydroxytoluene (BHT) and a complete mini-protease inhibitor (Roche Diagnostics, Indianapolis, IN) and assayed for protein concentration utilizing the Bradford assay. Protein $(50 \mu \mathrm{g})$ in PBS was blotted onto PVDF membranes. Blots were incubated with the primary antibody recognizing the Michael addition product of 4HNE-modified cellular proteins diluted 1:2,000 overnight at $4^{\circ} \mathrm{C}$ (37). Secondary antibody incubation was performed for $1 \mathrm{~h}$ with an HRP-conjugated goat anti-rabbit polyclonal antibody $(1: 25,000)$. Immunoreactive protein was detected using chemiluminescence (ECL Plus Western Blotting Detection System) on X-ray film. Analysis was performed by comparing 4HNE immunoreactive protein normalized to protein loading, determined by staining with India ink. Normalized average integrated densities were determined with ImageJ software (National Institutes of Health, Bethesda, MD).

\section{Statistical Analysis}

Student's $t$ tests were used to calculate statistical significance between two treatments, and one-way ANOVA tests were used to calculate statistical significance between more than two treatments. All experiments were performed in triplicate. Standard error of the mean (SEM) is reported by the error bars. All statistical analysis, unless otherwise specified, was 
performed in GraphPad Prism ${ }^{\circledR}$ (LaJolla, CA). P-AscH ${ }^{-}$toxicity curves were generated using IGOR Pro version 6.36 (WaveMetrics Inc., Lake Oswego, OR).

\section{RESULTS}

\section{Enhanced Ascorbate Oxidation Radiosensitizes PDAC}

Our previously published laboratory studies demonstrated that $\mathrm{P}-\mathrm{AscH}^{-}$radiosensitized PDAC (4). Similarly, P-AscH- in combination with MnT4MPyP as an oxidative catalyst exhibits enhanced cytotoxic effects by augmenting $\mathrm{H}_{2} \mathrm{O}_{2}$ generation (21). Clonogenic survival assays using a combination treatment of MnT4MPyP, $\mathrm{P}-\mathrm{AscH}^{-}$and irradiation in three PDAC cell lines demonstrated significant radiosensitization (Fig. 1A-C). Dose modifying factors calculated at 50\% iso-survival for each cell line were as follows: MIA PaCA-2 (2.7); AsPC-1 (2.6); and PANC-1 (3.1). There was no radiosensitization in the nontumorigenic H6c7 cell line (Fig. 1D).

In an effort to better simulate the tumor microenvironment, a 3D cell culture was created using the commercially available Cell-Mate3D system. With this technique, cells were embedded in a tissue matrix chemically composed of hyaluronic acid and chitosan (38). The cellular component was composed of MIA PaCa-2-Luc or PANC-1-Luc tumor cells and immortalized tumor-associated human pancreatic stellate cells (HSPCs). 3D cultures were suspended in media and treated with $\mathrm{P}-\mathrm{AscH}^{-}, \mathrm{MnT} 4 \mathrm{MPyP}$ and radiation (0-2 Gy). MIA $\mathrm{PaCa}-2-\mathrm{Luc}$ cells treated with MnT4MPyP alone, $\mathrm{P}-\mathrm{AscH}^{-}$alone, $1 \mathrm{~Gy}$ or $2 \mathrm{~Gy}$ irradiation alone experienced continued cell growth over $24 \mathrm{~h}$ that was similar to the growth of nontreated control cultures, as shown in Fig. 2A. However, cultures treated with combination MnT4MPyP and P-AscH ${ }^{-}$exhibited declines in bioluminescent signal strength (Fig. 2A). When cells received combined treatment with MnT4MPyP, $\mathrm{P}-\mathrm{AscH}^{-}$and radiation, an even greater decrease in signal strength was noted, demonstrating the enhanced cytotoxicity produced by combining all three treatment modalities, which when used individually, were not sufficient to produce tumor cytotoxicity in this simulated tumor microenvironment. Similar results were seen in the PANC-1 3D culture, with the combined treatment of MnT4MPyP, P-AscH ${ }^{-}$and radiation demonstrating the greatest decline in bioluminescent signal strength (Figure 2B).

\section{MnT4MPyP Increases Asc ${ }^{--}$Formation in Radiation Treatments}

To determine if the increased radiosensitivity in the presence of the MnT4MPyP combined with $\mathrm{P}-\mathrm{AscH}^{-}$was due to enhanced $\mathrm{P}-\mathrm{AscH}^{-}$oxidation catalyzed by MnT4MPyP, [Asc $\left.{ }^{--}\right]_{\mathrm{ss}}$ from the clonogenic survival assay culture media was measured by EPR. $\left[\mathrm{Asc}^{\circ}\right]_{\mathrm{ss}}$ translates to a proportional increase in the generation of $\mathrm{H}_{2} \mathrm{O}_{2}$, as we have reported elsewhere previously $(18,39)$. Figure $3 \mathrm{~A}$ and $\mathrm{B}$ show the respective $\left[\mathrm{Asc}^{-}{ }^{-}\right]_{\mathrm{ss}}$ from this experiment. In the presence of $\mathrm{P}-\mathrm{AscH}^{-}(0.20 \mathrm{mM})$ alone, the $\left[\mathrm{Asc}^{-}\right]_{\mathrm{ss}}$ was $300 \pm 30 \mathrm{n} M . \mathrm{P}-\mathrm{AscH}^{-}(0.20$ $\mathrm{m} M$ ) with 2 Gy irradiation increased the radical formation to $360 \pm 60 \mathrm{n} M$, but this difference was not statistically different from $\mathrm{P}-\mathrm{AscH}^{-}$treatment alone. The combination MnT4MPyP $(1 \mu M)$ with P-AscH ${ }^{-}(0.20 \mathrm{mM})$ increased the [Asc $\left.{ }^{-}\right]_{\mathrm{ss}}$ to $540 \pm 90 \mathrm{n} M$ and the addition of $2 \mathrm{~Gy}$ irradiation increased $\left[\mathrm{Asc}^{\circ}\right]_{\mathrm{ss}}$ to $770 \pm 150 \mathrm{n} M$ (means $\pm \mathrm{SEM}, \mathrm{n}=3$, $* P<0.05$ compared to $\mathrm{P}-\mathrm{AscH}^{-}$alone). 


\section{Enhanced Ascorbate Oxidation Radiosensitizes In Vivo}

We have previously demonstrated that MnT4MPyP and $\mathrm{P}-\mathrm{AscH}^{-}$inhibits tumor growth in vivo $(4,21,22)$. In the current experiment, we used a combination approach, i.e.,

MnT4MPyP with $\mathrm{P}-\mathrm{AscH}^{-}$and radiation, to explore the potential of this treatment in vivo. MIA PaCa-2-Luc human PDAC cells were used to facilitate tumor growth measurements via bioluminescent imaging. Tumor growth curves are shown in Fig. 4A. Saline-treated mice exhibited a rapid rate of tumor growth over the duration of the experiment with a nearly ninefold increase in tumor size. The irradiation group and the MnT4MPyP and P-AscH ${ }^{-}$ combined treatment group experienced similar rates of growth (1.6-and 2.1-fold difference from baseline, respectively). How ever, the mice that received combined treatment of MnT4MPyP, P-AscH and radiation exhibited an overall regression in tumor size from their baseline measurement (means \pm SEM, $\mathrm{n}=6-8$ per group, ${ }^{*} P<0.05$ vs. saline, ${ }^{\#} P<0.05$ vs. irradiation alone and MnT4MPyP with P-AscH ${ }^{-}$).

\section{Enhanced Ascorbate Oxidation In Vivo}

The average whole blood $\left[\mathrm{Asc}^{\circ}\right]_{\mathrm{ss}}$ for each treatment group is shown in Fig. 4B. Mice treated with saline had a mean $\left[\mathrm{Asc}^{\circ-}\right]_{\mathrm{ss}}$ of $2.0 \pm 0.6 \mathrm{n} M$ and mice receiving irradiation alone had a mean $\left[\mathrm{Asc}^{\circ-}\right]_{\mathrm{ss}}$ of $4.0 \pm 2.0 \mathrm{nM}$. However, there was a significant increase in $\left[\mathrm{Asc}^{\circ}{ }_{\mathrm{ss}}\right.$ to $30 \pm 7 \mathrm{n} M$ in mice treated with MnT4MPyP and $\mathrm{P}-\mathrm{AscH}^{-}$. Mice that received combined treatment of MnT4MPyP, P-AscH ${ }^{-}$and radiation showed the highest levels of $\left[\mathrm{Asc}^{\circ-}\right]_{\mathrm{ss}}$ with a mean of $160 \pm 35 \mathrm{nM}$, which was significantly increased compared to the other three treatment groups (means $\pm \mathrm{SEM}, \mathrm{n}=6-8, P<0.001$ ). In addition, excised tumors from mice that received combined treatment of MnT4MPyP, $\mathrm{P}-\mathrm{AscH}^{-}$and radiation demonstrated the highest levels of protein oxidation (Fig. 4C and D). Neither radiation alone, nor MnT4MPyP and $\mathrm{P}-\mathrm{AscH}^{-}$increased tumor $4 \mathrm{HNE}$ immunoreactivity from the levels measured in salinetreated mice. Only the combination of all three treatment modalities showed increased 4HNE levels within tumors.

\section{MnT4MPyP Increases P-AscH- Oxidation in Ex Vivo Human Plasma}

We sought to investigate the translational potential for MnT4MPyP to increase ascorbate oxidation in humans receiving $\mathrm{P}-\mathrm{AscH}^{-}$and radiation therapy for PDAC. We used plasma samples collected from our phase I clinical trial (NCT01852890) to test for changes in [Asc $\left.{ }^{-}\right]_{\text {ss }}$ with the addition of $1.0 \mu M$ of MnT4MPyP. Plasma specimens from six patients receiving $\mathrm{P}-\mathrm{AscH}^{-}$five days per week during their daily radiation treatments were also collected. A total of nine plasma samples were used for the control analysis, consisting of PDAC patients who received chemoradiation therapy but did not receive $\mathrm{P}-\mathrm{AscH}^{-}$as part of their treatment. Control patient samples were collected prior to treatment, during the third and sixth weeks of the standard chemoradiation cycle. Each plasma sample was tested for $\left[\mathrm{Asc}^{-}\right]_{\mathrm{ss}}$. The control, pretreatment and pre-infusion levels were comparable, while the P$\mathrm{AscH}^{-}$post-infusion plasma samples were significantly higher, as would be expected (Supplementary Fig. S1; http://dx.doi.org/10.1667/RR15189.1.S1). All plasma samples were then spiked with MnT4MPyP $(1.0 \mu M)$ and the samples were again tested for $\left[\mathrm{Asc}^{\circ-}\right]_{s s}$. The control, pretreatment, and pre-infusion sample $\left[\mathrm{Asc}^{\circ}\right]_{\mathrm{ss}}$ were each increased when spiked with MnT4MPyP compared to plasma samples alone (Supplementary Fig. S1). The post- 
infusion samples again showed significantly increased levels of $\left[\mathrm{Asc}^{-{ }^{-}}\right]_{\mathrm{ss}}$ when spiked with MnT4MPyP, from $400 \pm 85 \mathrm{n} M$ to $680 \pm 60 \mathrm{n} M$, indicating that a greater than $50 \%$ increase in ascorbate oxidation during radiation treatment is potentially achievable with the addition of MnT4MPyP (Fig. 5).

\section{DISCUSSION}

Radiation treatment is the standard-of-care therapy for PDAC in a variety of clinical indications ranging from curative to palliative intent. Thus, agents that increase the tumoricidal effect of radiation, which may conceivably prolong survival, are of great interest. Previously published studies from our laboratory have suggested that both manganoporphyrins and radiation, when combined with $\mathrm{PAscH}^{-}$, will increase tumor cytotoxicity $(4,21)$. Furthermore, our previously reported work has demonstrated that manganese porphyrins, such as MnT4MPyP, are capable of enhancing $\mathrm{P}-\mathrm{AscH}^{-}$oxidation, leading to overall toxicity. Others have also reported on the radioprotective effects generated from MnPs on normal tissue (23). It is therefore reasonable to investigate a treatment regimen that combines MnT4MPyP and $\mathrm{P}-\mathrm{AscH}^{-}$in the presence of radiation. To our knowledge, this is the first published in-depth investigation into the tumoricidal effects of a combined treatment regimen consisting of MnT4MPyP and $\mathrm{P}-\mathrm{AscH}^{-}$as a radiosensitizer in PDAC.

Our in vitro and in vivo studies presented here have demonstrated the potential of this potent treatment combination of MnT4MPyP, P-Asc $\mathrm{H}^{-}$and radiation. We have shown that tumor cells treated with MnT4MPyP combined with $\mathrm{P}-\mathrm{AscH}^{-}$are exposed to an oxidative flux that is far greater than MnT4MPyP or $\mathrm{P}-\mathrm{AscH}^{-}$alone. We also demonstrate the marked increase in toxicity when tumor cells treated with combined MnT4MPyP and $\mathrm{P}-\mathrm{AscH}^{-}$undergo radiation treatment. As our dose modification modeling illustrates, there is an increase in radiation toxicity with this multimodal approach. The capacity for each additional radiation dose to induce tumor cell toxicity is increased in cells treated with MnT4MPyP and P$\mathrm{AscH}^{-}$compared to untreated cells. However, when normal pancreatic ductal epithelial cells are treated with MnT4MPyP and $\mathrm{P}-\mathrm{AscH}^{-}$, then subsequently irradiated, there is no increase in radiation potency, indicating a selective toxicity for neoplastic cells.

These experiments demonstrated the increased sensitivity of PDAC to radiation in the presence of this combination treatment without any increase in radiosensitivity to normal pancreatic ductal epithelial cells. The 3D cell culture model highlights the potency of this treatment regimen. When tumor cells embedded in stromal cells and a biomatrix are treated in isolation with either MnT4MPyP, $\mathrm{P}-\mathrm{AscH}^{-}$or radiation, there was no observed effect on cell growth. Previously published experiments from our laboratory in the Mia PaCa- 2 cell line show a less than $10 \%$ cell survival in clonogenic survival experiments at similar treatment doses, but the simulated microtumor milieu in 3D cell cultures insulate the tumor cells from treatments added to the media. When $3 \mathrm{D}$ cultures were treated with a combination of MnT4MPyP and P-AscH ${ }^{-}$, a decrease was appreciated and escalating doses of radiation further increased the toxicity. 
Previously published studies have shown that the enhanced flux of oxidants produced by P$\mathrm{AscH}^{-}$leads to an increase in tumor toxicity (6). Our studies corroborate these findings by showing in vitro increases in $\left[\mathrm{Asc}^{-}\right]_{\mathrm{ss}}$ with combination MnT4MPyP and $\mathrm{P}-\mathrm{AscH}^{-}$. This pattern was again demonstrated in vivo by detecting increased levels of $\left[\mathrm{Asc}^{-}\right]_{\mathrm{ss}}$ in blood and detecting higher levels of $4 \mathrm{HNE}$ in the tumors of mice treated with combined treatment of MnT4MPyP, P-AscH and irradiation. Finally, we investigated the translational potential of this treatment regimen by adding MnT4MPyP to human PDAC patient plasma samples from patients receiving chemoradiation with and without $\mathrm{P}-\mathrm{AscH}^{-}$and testing for changes in [Asc $\left.{ }^{--}\right]_{\mathrm{ss}}$ as a measure of $\mathrm{P}-\mathrm{AscH}^{-}$oxidation and $\mathrm{H}_{2} \mathrm{O}_{2}$ production. Indeed, MnT4MPyP brought about remarkable increases in the rate of ascorbate oxidation, indicating an increased flux of $\mathrm{H}_{2} \mathrm{O}_{2}$.

Clinical trials for the use of $\mathrm{P}-\mathrm{AscH}^{-}$in PDAC are ongoing. A phase I clinical trial utilizing $\mathrm{P}-\mathrm{AscH}^{-}$with standard-of-care chemotherapy for patients with node-positive or metastatic PDAC demonstrated an exceptionally low toxicity profile with suggestion of treatment efficacy (7). Others have reproduced these results in a similar phase I/IIa study (8). In the future, manganese porphyrins may be considered as an investigational treatment regimen to add additional tumor toxicity and normal tissue protection. It is conceivable that agents such as these could enable an increase in the allowable radiation doses, making it possible for a greater proportion of patients with locally advanced disease to become resectable with a chance for disease control or even cure.

\section{Supplementary Material}

Refer to Web version on PubMed Central for supplementary material.

\section{ACKNOWLEDGMENT}

This study was supported by the National Institutes of Health (grant nos. CA184051, CA148062, CA078586 CA169046 and P30CA086862).

\section{REFERENCES}

1. Siegel RL, Miller KD, Jemal A. Cancer Statistics, 2017. CA Cancer J Clin 2017; 67:7-30. [PubMed: 28055103]

2. Howlader N, Noone AM, Krapcho M, Miller D, Bishop K, Kosary CL, editors. SEER Cancer Statistics Review, 1975-2014. Bethesda: National Cancer Institute; 2017 (https:// seer.cancer.gov/csr/1975_2014/)

3. Ghaneh P, Costello E, Neoptolemos JP. Biology and management of pancreatic cancer. Gut 2007; 56:1134-52. [PubMed: 17625148]

4. Du J, Cieslak JA, 3rd, Welsh JL, Sibenaller ZA, Allen BG, Wagner BA, et al. Pharmacological ascorbate radiosensitizes pancreatic cancer. Cancer Res 2015; 75:3314-26. [PubMed: 26081808]

5. Du J, Cullen JJ, Buettner GR. Ascorbic acid: chemistry, biology and the treatment of cancer. Biochim Biophys Acta 2012; 1826:443-57. [PubMed: 22728050]

6. Du J, Martin SM, Levine M, Wagner BA, Buettner GR, Wang SH, et al. Mechanisms of ascorbateinduced cytotoxicity in pancreatic cancer. Clin Cancer Res 2010; 16:509-20. [PubMed: 20068072]

7. Welsh JL, Wagner BA, van't Erve TJ, Zehr PS, Berg DJ, Halfdanarson TR, et al. Pharmacological ascorbate with gemcitabine for the control of metastatic and node-positive pancreatic cancer (PACMAN): results from a phase I clinical trial. Cancer Chemother Pharmacol 2013; 71:765-75. [PubMed: 23381814] 
8. Polireddy K, Dong R, Reed G, Yu J, Chen P, Williamson S, et al. High dose parenteral ascorbate inhibited pancreatic cancer growth and metastasis: mechanisms and a phase I/IIa study. Sci Rep 2017; 7:17188. [PubMed: 29215048]

9. Monti DA, Mitchell E, Bazzan AJ, Littman S, Zabrecky G, Yeo CJ, et al. Phase I evaluation of intravenous ascorbic acid in combination with gemcitabine and erlotinib in patients with metastatic pancreatic cancer. PLoS One 2012; 7:e29794. [PubMed: 22272248]

10. Buettner GR. The pecking order of free radicals and antioxidants: lipid peroxidation, alphatocopherol, and ascorbate. Arch Biochem Biophys 1993; 300:535-43. [PubMed: 8434935]

11. Levine M, Padayatty SJ, Espey MG. Vitamin C: a concentration-function approach yields pharmacology and therapeutic discoveries. Adv Nutr 2011; 2:78-88. [PubMed: 22332036]

12. Chen Q, Espey MG, Krishna MC, Mitchel JB, Corpe CP, Buettner GR, et al. Pharmacologic ascorbic acid concentrations selectively kill cancer cells: Action as a pro-drug to deliver hydrogen peroxide to tissues. Proc Natl Acad Sci U S A 2005; 102:13604-9. [PubMed: 16157892]

13. Chen Q, Espey MG, Sun AY, Lee JH, Krishna MC, Shacter E, et al. Ascorbic acid in pharmacologic concentrations: a pro-drug for selective delivery of ascorbate radical and hydrogen peroxide to extracellular fluid in vivo. Proc Natl Acad Sci U S A 2007; 104:8749-54. [PubMed: 17502596]

14. Doskey CM, Buranasudja V, Wagner BA, Wilkes JG, Du J, Cullen JJ, et al. Tumor cells have decreased ability to metabolize $\mathrm{H} 2 \mathrm{O} 2$ : Implications for pharmacological ascorbate in cancer therapy. Redox Biol 2016; 10:274-84. [PubMed: 27833040]

15. Levine M, Conry-Cantilena C, Wang Y, Welch RW, Washko PW, Dhariwal KR, et al. Vitamin C pharmacokinetics in healthy volunteers: evidence for a recommended dietary allowance. Proc Natl Acad Sci U S A. 1996; 93:3704-9. [PubMed: 8623000]

16. Padayatty S, Sun H, Wang Y, Riordan HD, Hewitt SM, Katz A, et al. Vitamin C pharmacokinetics: implications for oral and intravenous use. Ann Intern Med 2004; 140:533-7. [PubMed: 15068981]

17. Buettner GR, Jurkiewicz BA. Catalytic metals, ascorbate and free radicals: combinations to avoid. Radiat Res 1996; 145:532-41. [PubMed: 8619018]

18. Buettner GR, Jurkiewicz BA. Ascorbate free radical as a marker of oxidative stress: an EPR study. Free Radic Biol Med 1993; 14:49-55. [PubMed: 8384150]

19. Batinic-Haberle I, Reboucas JS, Spasojevic I. Superoxide dismutase mimics: chemistry, pharmacology, and therapeutic potential. Antioxid Redox Signal 2010; 13:877-918. [PubMed: 20095865]

20. Batinic-Haberle I, Rajic Z, Benov L. A combination of two antioxidants (an SOD mimic and ascorbate) produces a prooxidative effect forcing Escherichia coli to adapt via induction of oxyR regulon. Anticancer Agents Med Chem 2011; 11:329-40. [PubMed: 21355843]

21. Rawal M, Schroeder SR, Wagner BA, Cushing CM, Welsh J, Button AM, et al. Manganoporphyrins increase ascorbate-induced cytotoxicity by enhancing $\mathrm{H}(2) \mathrm{O}(2)$ generation. Cancer Res 2013; 73:5232-41. [PubMed: 23764544]

22. Cieslak JA, Strother RK, Rawal M, Du J, Doskey CM, Schroeder SR, et al. Manganoporphyrins and ascorbate enhance gemcitabine cytotoxicity in pancreatic cancer. Free Radic Biol Med 2015; 83:227-37. [PubMed: 25725418]

23. Chatterjee A, Zhu Y, Tong Q, Kosmacek EA, Lichter EZ, Oberley-Deegan RE. The addition of manganese porphyrins during radiation inhibits prostate cancer growth and simultaneously protects normal prostate tissue from radiation damage. Antioxidants 2018; 7:21.

24. Kobayashi J, Iwabuchi K, Miyagawa K, Sonoda E, Suzuki K, Takata M, et al. Current topics in DNA double-strand break repair. J Radiat Res 2008; 49:93-103. [PubMed: 18285658]

25. Szatrowski TP, Nathan CF. Production of large amounts of hydrogen peroxide by human tumor cells. Cancer Res 1991; 51:794-8. [PubMed: 1846317]

26. Oberley LW. Mechanism of the tumor suppressive effect of MnSOD overexpression. Biomed Pharmacother 2005; 59:143-8. [PubMed: 15862707]

27. Du J, Nelson ES, Simons AL, Olney KE, Moser JC, Schrock HE, et al. Regulation of pancreatic cancer growth by superoxide. Mol Carcinog 2013; 52:555-67. [PubMed: 22392697]

28. Begg AC, Stewart FA, Vens C. Strategies to improve radiotherapy with targeted drugs. Nat Rev Cancer 2011; 11:239-53. [PubMed: 21430696] 
29. Moser JC, Rawal M, Wagner BA, Du J, Cullen JJ, Buettner GR. Pharmacological ascorbate and ionizing radiation (IR) increase labile iron in pancreatic cancer. Redox Biol 2013; 2:22-7. [PubMed: 24396727]

30. Hwang RF, Moore T, Arumugam T, Ramachandran V, Amos KD, Rivera A, et al. Cancerassociated stromal fibroblasts promote pancreatic tumor progression. Cancer Res 2008; 68:91826. [PubMed: 18245495]

31. O'Leary BR, Fath MA, Bellizzi AM, Hrabe JE, Button AM, Allen BG, et al. Loss of SOD3 (EcSOD) expression promotes an aggressive phenotype in human pancreatic ductal adenocarcinoma. Clin Cancer Res 2015; 21:1741-51. [PubMed: 25634994]

32. Muniz VP, Barnes JM, Paliwal S, Zhang X, Tang X, Chen S, et al. The ARF tumor suppressor inhibits tumor cell colonization independent of p53 in a novel mouse model of pancreatic ductal adenocarcinoma metastasis. Mol Cancer Res 2011; 9:867-77. [PubMed: 21636682]

33. Schoenfeld JD, Sibenaller ZA, Mapuskar KA, Wagner BA, Cramer-Morales KL, Furqan M, et al. $\mathrm{O} 2$ - and H2O2-mediated disruption of Fe metabolism causes the differential susceptibility of NSCLC and GBM cancer cells to pharmacological ascorbate. Cancer Cell 2017; 31:487-500, e8. [PubMed: 28366679]

34. Buettner GR, Kiminyo KP. Optimal EPR detection of weak nitroxide spin adduct and ascorbyl free radical signals. J Biochem Biophys Meth 1992; 24:147-51. [PubMed: 1313843]

35. Allen BG, Bhatia SK, Buatti JM, Brandt KE, Lindholm KE, Button AM, et al. Ketogenic diets enhance oxidative stress and radio-chemo-therapy responses in lung cancer xenografts. Clin Cancer Res 2013; 19:3905-13. [PubMed: 23743570]

36. Ayala A, Munoz MF, Aguelles S. Lipid peroxidation: production, metabolism, and signaling mechanisms of malondialdehyde and 4-hydroxy-2-nonenal. Oxid Med Cell Longev 2014; 2014:31.

37. Cohn JA, Tsai L, Friguet B, Szweda LI. Chemical characterization of a protein-4-hydroxy-2nonenal cross-link: immunochemical detection in mitochondria exposed to oxidative stress. Arch Biochem Biophys 1996; 328:158-64. [PubMed: 8638925]

38. Chai YW, Lee EH, Gubbe JD, Brekke JH. 3D cell culture in a self-assembled nanofiber environment. PloS One 2016; 11:e0162853. [PubMed: 27632425]

39. Chen Q, Espey MG, Sun AY, Lee JH, Krishna MC, Shacter E, et al. Ascorbate in pharmacologic concentrations selectively generates ascorbate radical and hydrogen peroxide in extracellular fluid in vivo. Proc Natl Acad Sci U S A. 2007; 104:8749-54. [PubMed: 17502596] 

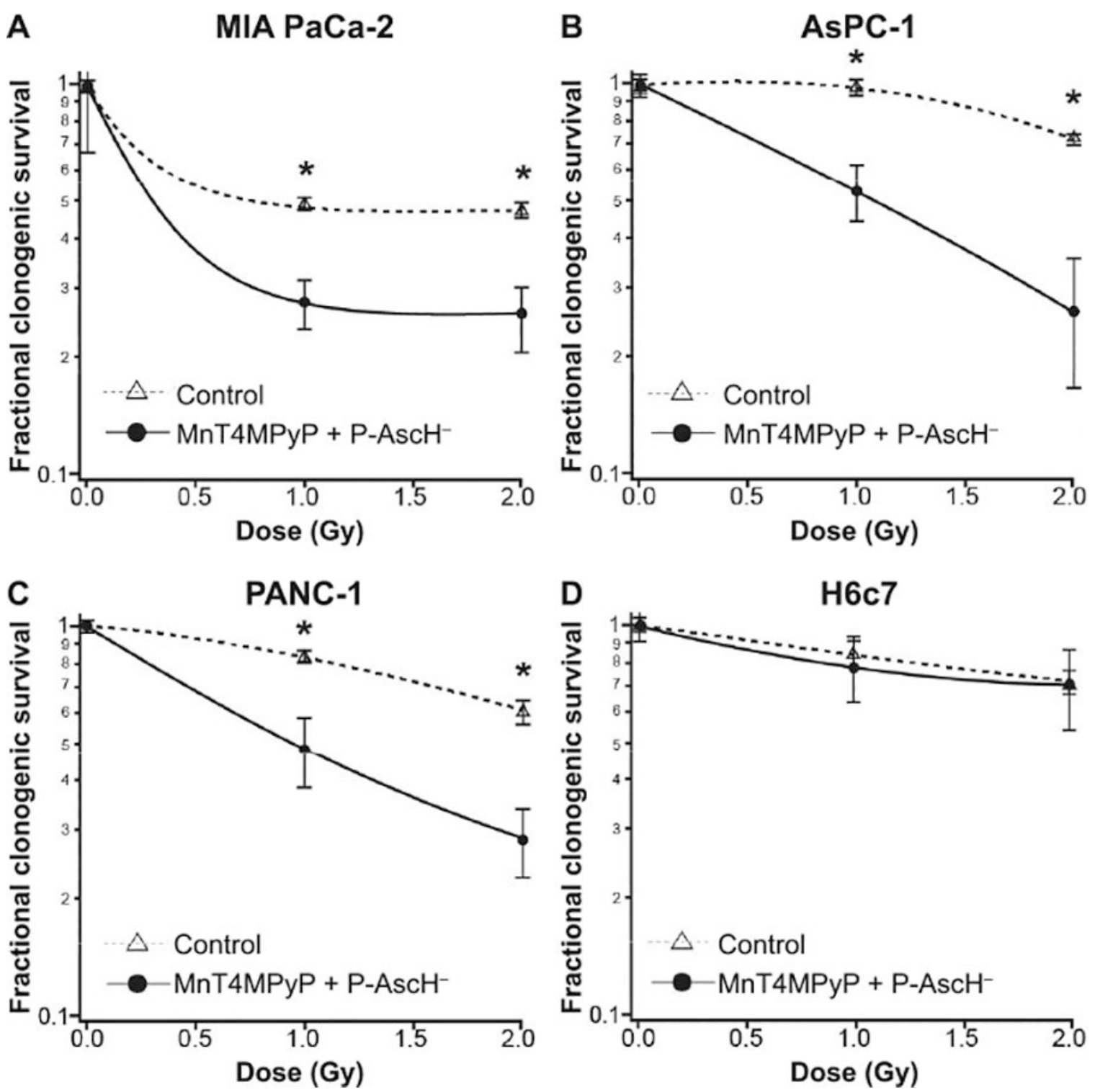

FIG. 1.

Panels A-D: MIA PaCa-2 PDAC cells, AsPC-1 PDAC cells, PANC-1 PDAC cells and H6c7 human nontumorigenic pancreatic ductal epithelial cells, respectively, were irradiated (0-2 Gy) with and without combination treatment of MnT4MPyP $(1 \mu M)$ and $\mathrm{P}-\mathrm{AscH}^{-}(0.2 \mathrm{~m} M)$. Clonogenic survival was determined and toxicity curves were generated. For the MIA PaCa-2, AsPC-1 and PANC-1 PDAC cells (panels A-C), the resulting dose modification factors at 50\% iso-survival were 2.7, 2.6 and 3.1, respectively, all of which indicated radiosensitization $(* P<0.01$ vs. radiation alone, means \pm SEM, $\mathrm{n}=3$ per group). In the H6c7 cells (panel D), there was no radiosensitization $(P>0.05$ vs. radiation alone, means \pm SEM, $\mathrm{n}=3$ ). 

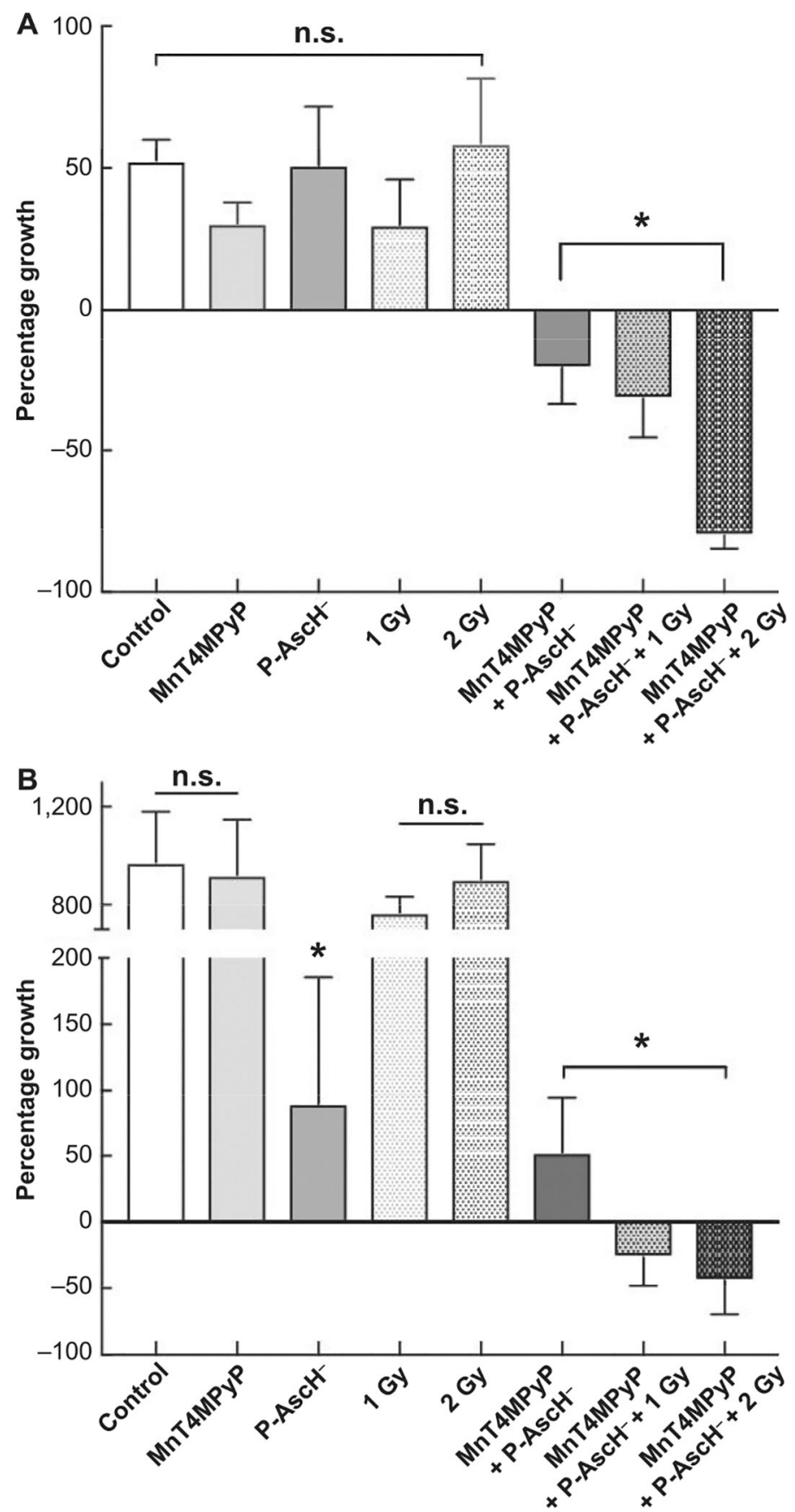

FIG. 2.

Enhanced ascorbate oxidation radiosensitizes PDAC cells in 3D culture. Panel A: MIA

$\mathrm{PaCa}-2$-Luc cells were mixed with human pancreatic stellate cells at a ratio of 1:19 (5\% cancer cells) and suspended in a 3D cell culture matrix to simulate the tumor microenvironment. Cultures were treated with MnT4MPyP $(2 \mu M)$ and P-AscH ${ }^{-}(7 \mathrm{~m} M)$ for $1 \mathrm{~h}$ and irradiated at $0-2 \mathrm{~Gy}$. The 24-h change in BOI after treatment was measured. MnT4MPyP, P-Asc $\mathrm{H}^{-}$and $1 \mathrm{~Gy}$ or $2 \mathrm{~Gy}$ radiation alone had no effect on bioluminescent expression compared to control. Combination treatment with MnT4MPyP and P-AscH ${ }^{-}$ resulted in a decreased bioluminescence while the addition of radiation further reduced the 
bioluminescence. ( $*<0.05$ compared to control, means \pm SEM, $\mathrm{n}=3$ ). Panel B: PANC-1Luc cells were mixed with human pancreatic stellate cells in a ratio of 3:17 (15\% cancer cells) and suspended in a 3D cell culture matrix and treated with MnT4MPyP $(2 \mu M)$ and P$\mathrm{AscH}^{-}(7 \mathrm{mM})$ for $1 \mathrm{~h}$ and irradiated at 0-2 Gy. Treatments were repeated every $48 \mathrm{~h}$ for a total of three treatments. The 144-h change in BOI after all three treatments was measured, and demonstrated decreased bioluminescence in cultures treated with combination MnT4MPyP and $\mathrm{P}-\mathrm{AscH}^{-}$. The addition of radiation further reduced the bioluminescence. $(* P<0.05$ compared to control, means \pm SEM, $\mathrm{n}=3$ ). 
A
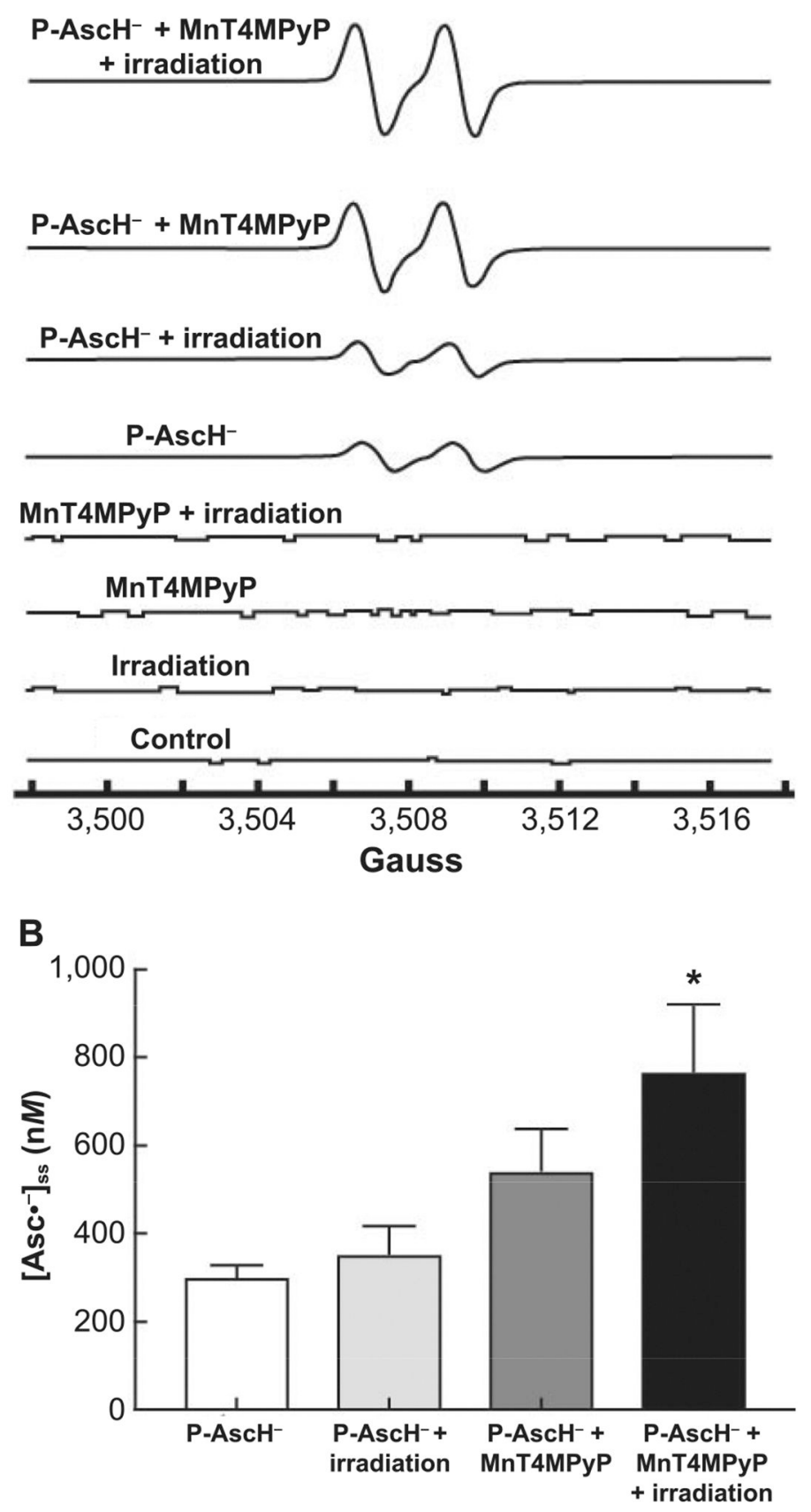

FIG. 3.

MnT4MPyP increases P-AscH ${ }^{-}$oxidation. Panel A: Media was collected immediately after treatment of MIA PaCa- 2 cells $\left(2.5 \times 10^{5}\right.$ cells $)$ with MnT4MPyP $(1 \mu M)$ and P-AscH ${ }^{-}(0.2$ $\mathrm{m} M$ ) with or without irradiation $(2 \mathrm{~Gy})$. Steady-state ascorbate radical [Asc $\left.{ }^{\bullet-}\right]_{\mathrm{ss}}$ was measured by EPR. There was no detectable Asc ${ }^{\bullet-}$ observed in media from control cells, MnT4MPyP-treated cells, 2 Gy irradiated cells or combination (2 Gy irradiation and MnT4MPyP) -treated cells. [Asc $\left.{ }^{\bullet-}\right]_{\text {Ss }}$ EPR spectra were detectable in the media after treatment with $\mathrm{P}-\mathrm{AscH} \mathrm{H}^{-}, \mathrm{P}-\mathrm{AscH}^{-}$combined with $2 \mathrm{~Gy}$ irradiation, MnT4MPyP combined 
with $\mathrm{P}-\mathrm{AscH}^{-}$and $\mathrm{MnT} 4 \mathrm{MPyP}$ combined with $\mathrm{P}-\mathrm{AscH}^{-}$and $2 \mathrm{~Gy}$ irradiation. Amplitudes correspond to $\left[\mathrm{Asc}^{-}\right]_{\mathrm{ss}}$. Panel B: $\left[\mathrm{Asc}^{\circ-}\right]_{\mathrm{ss}}$ determined by EPR is quantified and displayed for the following: P-AscH ${ }^{-}=300 \pm 30 \mathrm{n} M ; \mathrm{P}-\mathrm{AscH}^{-}+2 \mathrm{~Gy}=360 \pm 60 \mathrm{n} M ; \mathrm{P}-\mathrm{AscH}^{-}+$ MnT4MPyP $=540 \pm 90 \mathrm{n} M$; and P-AscH ${ }^{-}+\mathrm{MnT} 4 \mathrm{MPyP}+2 \mathrm{~Gy}=770 \pm 150 \mathrm{nM} .{ }^{*} P<$ 0.05 compared to $\mathrm{P}-\mathrm{AscH}^{-}$means $\pm \mathrm{SEM}, \mathrm{n}=3$ ). 

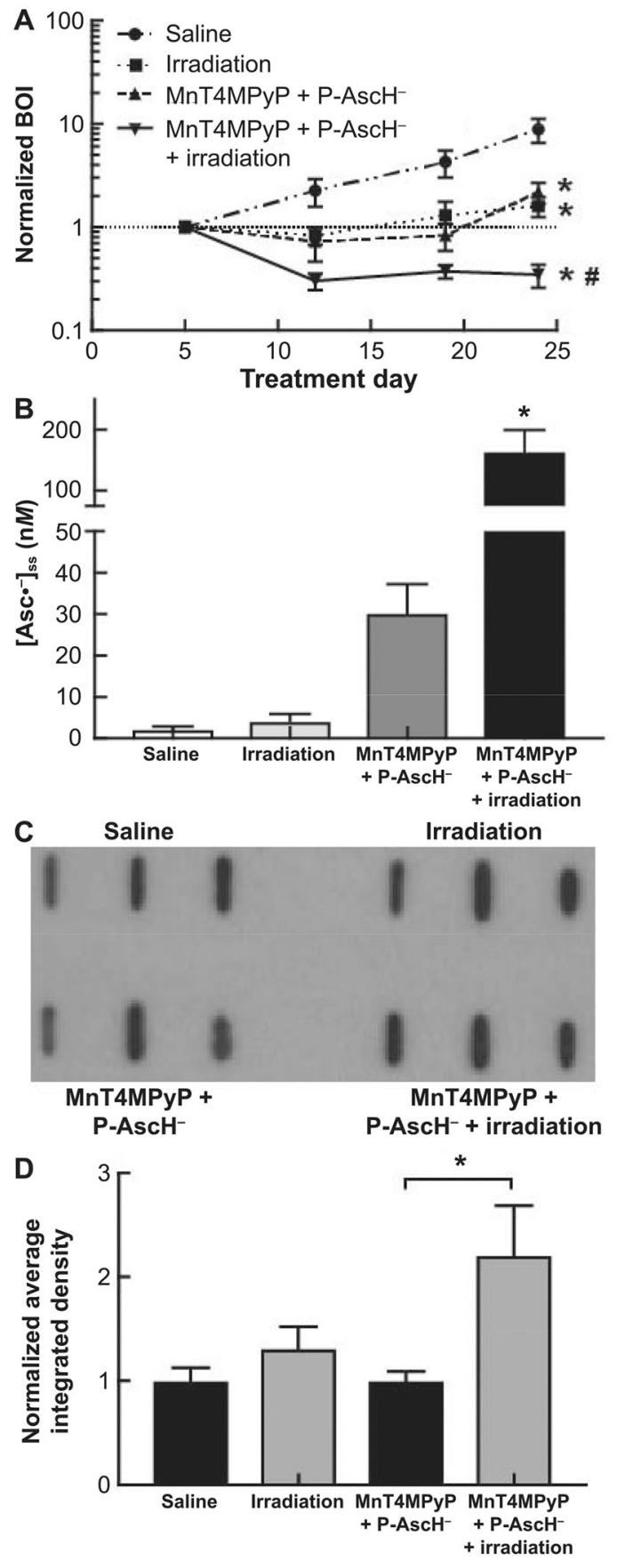

FIG. 4.

Enhanced ascorbate oxidation radiosensitizes in vivo PDAC growth and increases tumor oxidative stress. Panel A: Mice were injected subcutaneously with $3 \times 10^{6}$ MIA PaCa-2-Luc tumor cells. Once tumors could be imaged by bioluminescence, mice were randomized into one of four experimental treatment groups: saline alone; saline and irradiation; MnT4MPyP and $\mathrm{P}-\mathrm{AscH}^{-}$; and $\mathrm{MnT} 4 \mathrm{MPyP}$ with $\mathrm{P}-\mathrm{AscH}^{-}$and irradiation. The first day of treatment was considered day 1 and treatments continued for 24 days. Saline was given at a dose of $1 M$ $\mathrm{NaCl}$ daily. MnT4MPyP was delivered at $1 \mathrm{mg} / \mathrm{kg}$ per day s.c. P-AscH ${ }^{-}$was delivered at 4 
g/kg per day i.p. A dose of 5 Gy radiation was delivered to each flank tumor on days 4,11 and 18 of treatment. In animal tumors treated with radiation alone or with combination MnT4MPyP and $\mathrm{P}-\mathrm{AscH}^{-}$, tumor growth inhibition was observed compared to saline-treated animals $(* P<0.05$, means \pm SEM, $\mathrm{n}=12-14)$. However, mice treated with MnT4MPyP combined with $\mathrm{P}-\mathrm{AscH}^{-}$and irradiation had the greatest inhibition of tumor growth compared to saline $(* P<0.05)$ and irradiation alone or MnT4MPyP combined with P$\mathrm{AscH}^{-}\left({ }^{\#} P<0.05\right.$, means $\left.\pm \mathrm{SEM}\right)$. Panel B: $\left[\mathrm{Asc}^{\bullet-}\right]_{\mathrm{ss}}$ was determined by EPR, demonstrating significant increase in groups of mice treated with MnT4MPyP combined with $\mathrm{PAscH}^{-}(30$ $\mathrm{n} M \pm 7, \mathrm{n}=6)$ and MnT4MPyP combined with P-AscH ${ }^{-}$and irradiation $(160 \mathrm{n} M \pm 35, \mathrm{n}=$ 6 , ${ }^{*} P<0.05$, means \pm SEM). Panel C: Representative protein oxidation as measured by 4HNE in tumors from each group after treatment with saline, MnT4MPyP, $\mathrm{PAscH}^{-}$and $5 \mathrm{~Gy}$ irradiation. Panel D: 4HNE immunoreactive protein quantified from tumor samples using ImageJ software, normalized to saline controls. Tumors of mice treated with MnT4MPyP combined with $\mathrm{P}-\mathrm{AscH}^{-}$and irradiation experienced higher levels of protein oxidation compared to MnT4MPyP combined with P-AscH ${ }^{-}(* P<0.05$, means \pm SEM). 


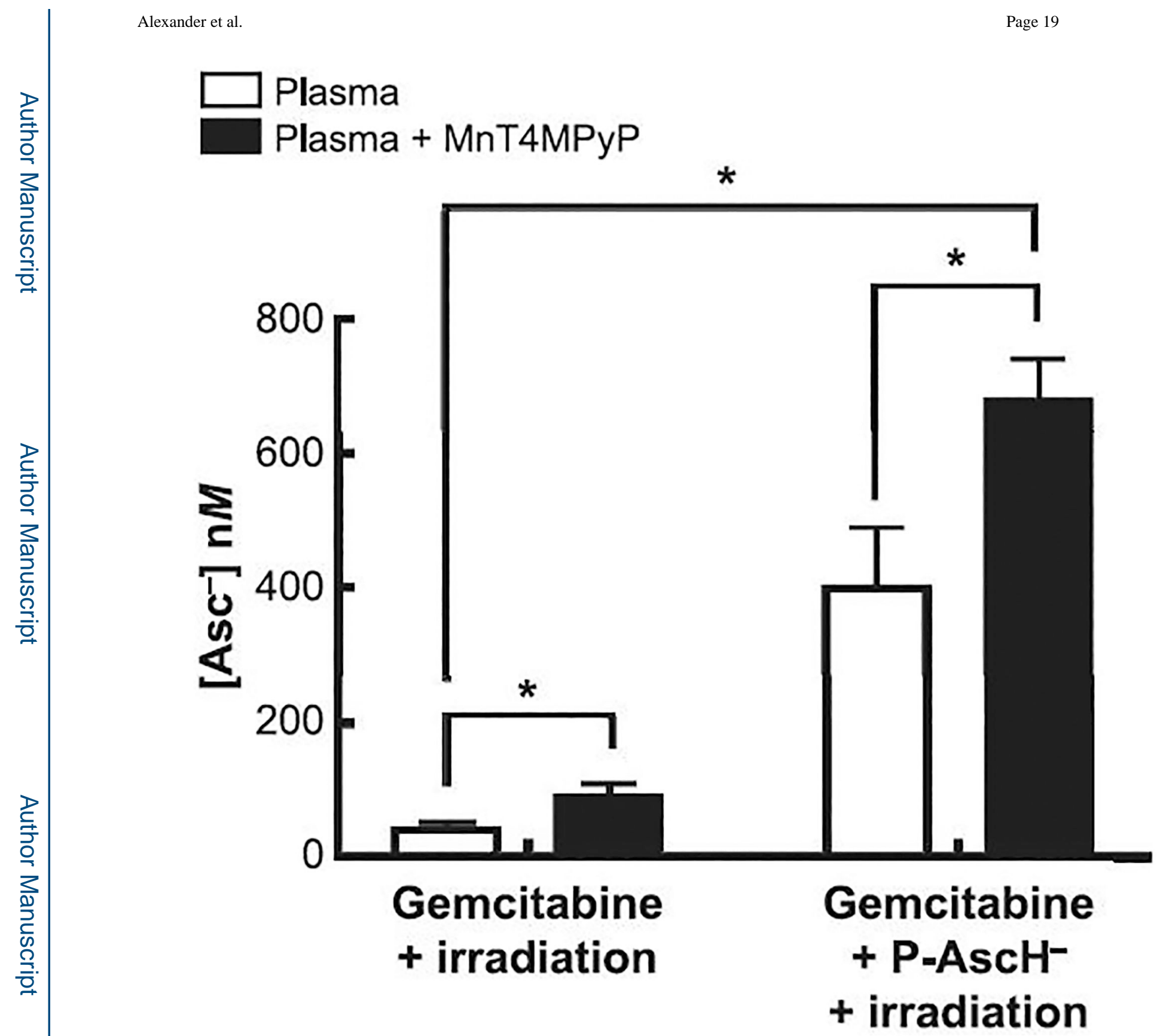

FIG. 5.

MnT4MPyP enhances ascorbate oxidation in human plasma. Plasma samples were collected from patients enrolled in the phase I clinical trial (NCT01852890). [Asc $\left.{ }^{\circ-}\right]_{\mathrm{ss}}$ in the plasma of participants receiving gemcitabine combined with radiation treatment was detected (40 \pm 6 $\mathrm{n} M, \mathrm{n}=9)$. When MnT4MPyP $(1 \mu M)$ was added to the plasma samples of patients treated with gemcitabine and radiation, the $\left[\mathrm{Asc}^{--}\right]_{\mathrm{ss}}$ was significantly increased $(90 \pm 6 \mathrm{n} M, \mathrm{n}=9$; $* P<0.05$, means \pm SEM). Next, in the plasma from participants treated with gemcitabine combined with radiation and $\mathrm{P}-\mathrm{AscH}^{-},\left[\mathrm{Asc}^{\circ-}\right]_{\mathrm{ss}}$ levels were measured $(400 \pm 85, \mathrm{nM}, \mathrm{n}=$ 6); MnT4MPyP $(1 \mu M)$ was added to these plasma samples and again, the $\left[\mathrm{Asc}^{-{ }^{-}}\right]_{\mathrm{ss}}$ significantly increased $(680 \pm 6 \mathrm{n} M, \mathrm{n}=6 ; * P<0.05$, means \pm SEM $)$. 